\title{
Invention Zaman Barok dan Pengembangan Permainan Piano
}

\author{
RIANTI MARDALENA PASARIBU ${ }^{*}$ \\ Jurusan Musik, Fakultas Seni Pertunjukan, Institut Seni Indonsia Yogyakarta.
}

\begin{abstract}
Invention in Barok Era and The Development of Piano Lesson. In piano lesson, one material of parts to which had been given is polyphony, which is an Invention from J.S. Invention is a basic finger-skill for pianist. Invention develops in the Baroque period. The baroque ideology is not only called as the reaction of Renaissance, but also as the continuing development from Renaissance. Invention is known in two forms. First is as a piano composition and second is as a piano play which can push a pianist to understand more about an arrangement that he played and expressed.
\end{abstract}

Keywords: Piano, J.S. Bach, and invention

\section{Pendahuluan}

Salah satu bagian materi yang diberikan dalam pelajaran piano adalah bentuk polifoni yaitu Invention dari J. S. Bach. Invention merupakan suatu dasar ketrampilan jari seorang pemain piano. Teknik invention ini mempunyai ciri tersendiri. Pokok inilah yang akan dibahas dalam artikel ini yakni bagaimana Bach pada awalnya menciptakan Invention tersebut dilihat dari segi bentuk, jalinan melodi dan harmoni, serta bagaimana pada akhirnya teknik tersebut dapat membantu seorang pemain piano dalam membuat ekspresi untuk mengeluarkan masing-masing suara tema yang harus ditonjolkan.

Invention Bach ternyata dapat dipakai sebagai contoh dalam bidang komposisi. Maksudnya, seseorang dapat pula mempraktikkan pola penggubahan komposisi baru dengan mengikuti pola Invention Bach ini.

Untuk dapat di mainkan Invention dengan baik, invention ini memerlukan prasyarat tertentu. Ada dua syarat yang harus dipenuhi, yaitu, pertama, seorang pemaian piano harus mengenal sang komponis; dan kedua, mengetahui latar belakang penciptaan karya tersebut.

Pada bagian berikut, penulis secara fokus akan membahas, hal-hal: pertama, periode Barok sebagai periode dari lahirnya Invention; kedua, J. S. Bach sebagai salah seorang komponis zaman Barok; dan penekanan pada analisis Invention dua suara no. 1 .

\section{Pembahasan}

Aliran Barok adalah aliran yang menggantikan aliran Renaissance. Tentang permulaan dan akhir dari aliran Barok, para ahli mempunyai pendapat yang sering berbeda, tetapi pada umumnya aliran Barok dimulai sekitar 1600 dan berakhir sekitar 1750 (meninggalnya Bach).

Reigo Reiman misalnya, salah satu tokoh zaman Barok sama sekali tidak memakai istilah Barok. Ia menyebut zaman di atas (1600-1750) sebagai periode General Bas. Mengapa Reiman menyebut demikian? Tidak lain karena salah satu ciri yang menonjol dari zaman tersebut adalah praktik yang disebut Bas Berangka. Bas Berangka artinya iringan piano atau orgel, baik ia berfungsi sebagi iringan, alat musik solo, atau solo yang berperan di dalam sebuah orkestra. Di sini penulisannya hanya mencatat Bas musik dan akorakor yang diperlukan dengan cara membubuhi dengan angka-angka.

Dalam hubungan ini, kita dapat mengemukakan beberapa komponis yang dapat dianggap

\footnotetext{
*Alamat korespondensi: Jln. Parangtritis km.6,5 Sewon Yogyakarta 55001. Tlp. 0274-375380.e-mail: rianti_mp@yahoo.co.id
} 
sebagai tokoh zaman Barok, misalnya: Vivaldi (Italia), Rameau (Paris), Lully (Paris), Henry Purcell (London), Telemann (Hamburg), Handel (Hamburg) dan Bach (Leipzig).

Aliran Barok, selain dapat dikatakan sebagai reaksi terhadap Renaissance, juga merupakan pengembangan lanjut dari Renaissance. Gaya monodies di Renaissance pada hakekatnya merupakan penonjolan melodi, sementara yang lain hanya bertindak sebagai iringan. Gaya ini mendapat perkembangannya di dalam Barok lewat yang menampakkan diri di dalam permainan solo. Beberapa contoh yang bisa dirujuk, misalnya: Konserto biola, solo Aria dalam opera, Kantata dan Oratorium dalam bentuk-bentuk yang timbul pada zaman Barok.

Sebaliknya, Barok juga menghidupkan kembali musik polifonis yang dapat disebut praRenaissance. Musik ini mencakup baik musik vokal maupun musik instrumental. Kita dapat mengenali puncak pencapaiannya pada Preludium dan Fuga untuk orgel maupun Klavier (piano) seperti yang ditemukan dalam Das Wohltemperierte Clavier, termasuk juga Invention dua atau tiga suara yang akan diulas berikut ini. Pun kita mengerti, bahwa Invention dua atau tiga suara ini dapat dianggap sebagai usaha untuk menghidupkan kembali gaya polifoni yang justru dielakkan oleh Renaissance. Namun, ada baiknya, sebelum membahas Invention, kita akan membicarakan terlebih dulu tentang J. S. Bach.

J. S. Bach berasal dari keluarga pemusik yang telah turun temurun berada di Thüringen, Jerman. J. S. Bach lahir pada 21 Maret 1685 di Eisenach sebagai anak ke-8 dari Ambrosius Bach dan Elizabeth Lämmerkrit. Pada usia sembilan tahun ayahnya meninggal dan setahun kemudian ibunya meninggal pula. Sejak itu dia tinggal bersama abangnya yang tertua Johann Christopher yang menjadi organis di Ohrdruf.

Tahun 1700 Bach mengunjungi Michaelisschule (kira-kira setaraf dengan tingkat SMA) di Lüneburg. Dari kota ini Bach mempunyai kesempatan untuk mengunjungi dan mendengar permainan orgel Reineche di Hamburg. Dari Lüneburg ini juga dia mendapat kesempatan ke Celle untuk mendengar musik Perancis yang banyak dimainkan di sana. Setelah tinggal di Lüneburg Bach pindah ke Weimar, tempat dia bekerja sebagai violis di Kapelle walaupun untuk waktu yang tidak lama (1703-1704).

Pada tahun 1705 Bach menjadi organis di Arnstadt. Di kota ini dia menggubah musik gereja yang pertama, dan di kota ini pulalah ia menggubah Capricio, komposisi yang terkenal itu.

Adanya pertentangan-pertentangan antara golongan atas di Arnstadt mendorong Bach pindah ke Mülhausen 1707, tempat dia menjadi organis pada gereja St. Blasius. Di kota ini pula ia menikah dengan Maria Barbara. Tetapi di sini juga ada pertentangan antara aliran ortodok dan pietis (yang tidak menyenangi musik), dan ini mendorong Bach pergi ke Weimar 1708, tempat dia menjadi organis istana di samping juga sebagai pemain biola di Kapelle dari Herzog Wilhelm Erns.

Dari Weimar tiap tahun Bach mengadakan perjalanan konser: ke Halle (1713), Kassel, dan Leipzig, tempat dia bertemu dengan Kuhnau (1714), kembali lagi ke Halle (1716), dan Leipzig serta Dresden (1717). Sebagai pemain orgel, pada waktu itu Bach sudah terkenal. Di Weimar inilah hadir gubahan-gubahan untuk instrumen orgel, antara lain 8 Kleine Preludium und Fugen. Juga, di Weimar inilah dia mempelajari musik Italia, seperti musik Vivaldi yang khusus untuk orgel.

Pada Natal 1717 Bach menjadi Kammermusik director di Köthen, yang sebenarnya merupakan kemunduran bagi Bach karena raja di sana seorang Calvinist yang tidak memberi banyak peluang untuk perkembangan musik gereja.

Pada 1720 isterinya meninggal. Dari ketujuh anaknya hanya empat yang masih hidup, yaitu satu putri dan tiga putra: W. Friedeman (17171784), Carl Philip Emanuel (1714-1788) dan Johann Gottfrit (1714-1739). Satu setengah tahun kemudian Bach menikah lagi dengan Anna Magdalena Wülken. Di Kota Köthen ini Bach membuat gubahannya, yaitu: Clavier büchlein für W. Fr. Bach dan Clavier büchlein für Anna Magdalena Bach. Di Kota Kothen pula Bach menggubah Das Wohltemperierte Clavier dan Invention dua atau tiga suara yang akan dibahas di bagian berikut.

Pada 1722, Kuhnau yang menjadi organis di Leipzig meninggal dunia dan Bach melamar sebagai pengganti. Dia di terima pada 5 Mei 1723 
(dengan catatan karena tidak ada yang lebih baik). Sejak itu dia menjadi kantor di gereja Thomas di Leipzig. Di kota inilah Bach sangat produktif dengan melahirkan gubahan-gubahan antara lain: Matheus Passion, Weinachtsoratorium dan lain-lain yang mengabadikan namanya untuk masa yang akan datang.

\section{Invention Dua Suara No.1}

Seperti yang dijelaskan sebelumnya, bahwa kumpulan Invention terutama dimaksudkan sebagai bahan untuk mereka yang mempelajari piano, dan juga untuk menunjukkan bagaimana mereka yang ingin mengetahui tentang cara memainkan dua atau tiga suara yang benar. Selain itu, kumpulan di atas dimaksudkan pula untuk mempraktikkan Invention, yang berarti menggubahnya. Dengan demikian, Invention pada hakikatnya dimaksudkan juga sebagai contoh untuk komposisi.

Analisis Invention dua suara Bach, penulis terutama menitikberatkan usahanya pada hal-hal berikut: Analisa bentuk, analisa teknik pembuatan melodi dan harmoni, yang pada akhirnya diperlukan suatu ekspresi dalam memainkannya.

\section{Invention Nomor 1 dalam C Mayor}

Invention ini terdiri dari 22 birama, dapat dibagi dalam 3 bagian: (a) bagian pertama terdiri dari birama 1-7, (b) bagian kedua dari birama $7-$ 15, (c) bagian ketiga dari birama 15-22.

Berikut ini Invention bagian pertama yang terdiri dari birama 1-7:
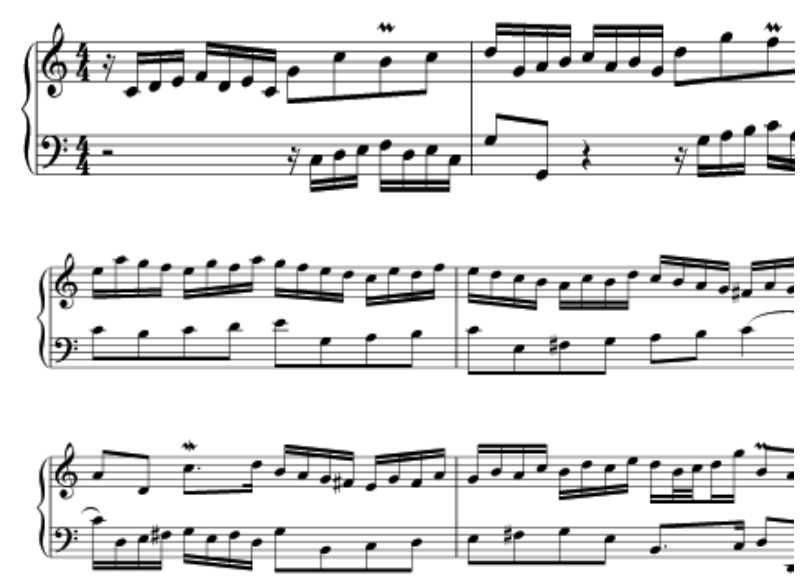

Tema terdiri dari gabungan dua motif pendek, yaitu:

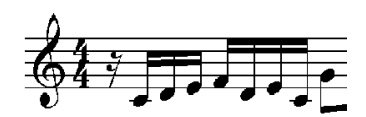

motif a

dan

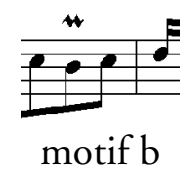

Pertama kali tema dimainkan dengan tangan kanan dalam Tonika, dan langsung ditirukan dengan tangan kiri bersamaan dengan munculnya motif b pada tangan kanan, kemudian dilanjutkan dengan ulangan tema dalam Dominan. Jadi, dalam birama 1-2 tema diperkenankan dalam tingkat Tonika-Dominan-Tonika (I-V-I).

Birama 3-4 berupa pengolahan motif a, yang arah nadanya dibalik atau inversi.

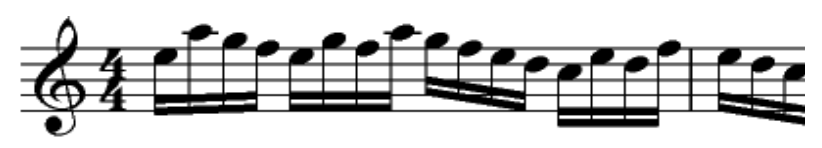

Birama 5-6 merupakan penyelesaian dari birama 3-4, yaitu dengan menirukan motif a pada tangan kanan, yang arah nadanya dibalik dan selanjutnya bermodulasi ke G Mayor (birama 7).

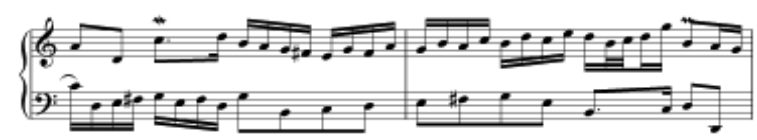

Berikut ini Invention bagian kedua yang terdiri dari birama 7-15:
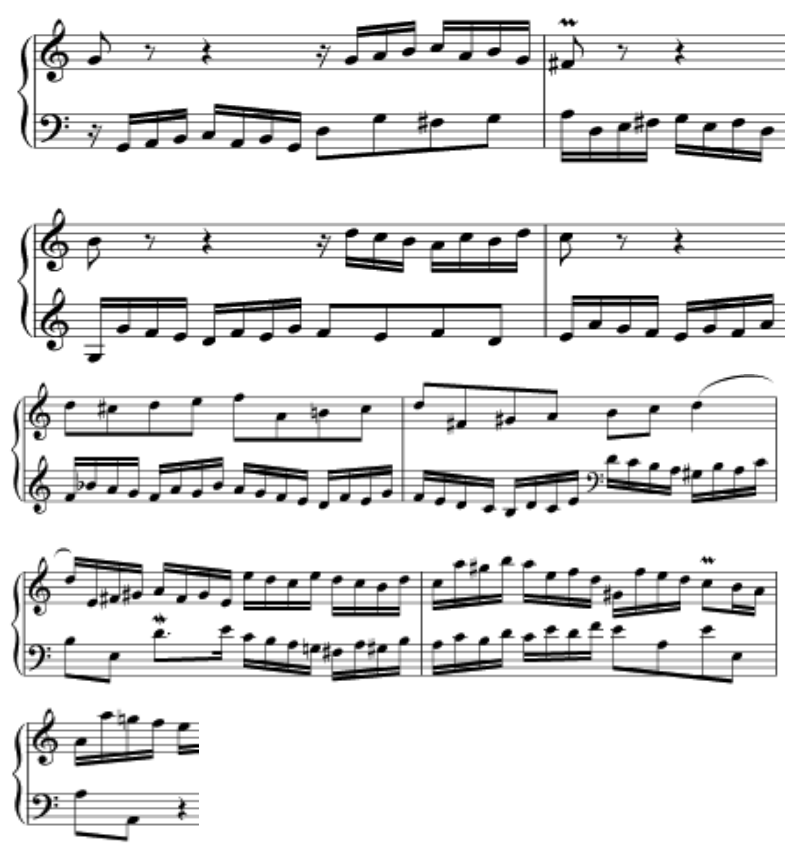

Pada birama 7-8 tema muncul kembali sama dengan birama 1-2, tetapi sudah dengan pertukaran suara. 


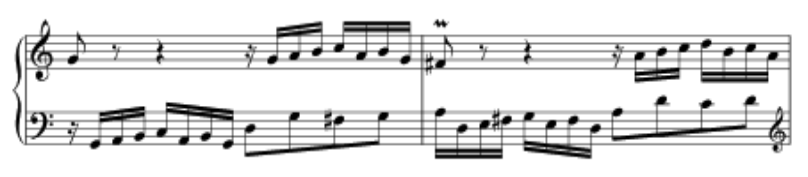

Selanjutnya pada birama 9-10, gerakan melodinya kebalikan dari birama 7-8. Birama 11-14 sama dengan birama 3-6, tetapi sudah dengan pertukaran suara dan bermodulasi ke a minor (birama 15).

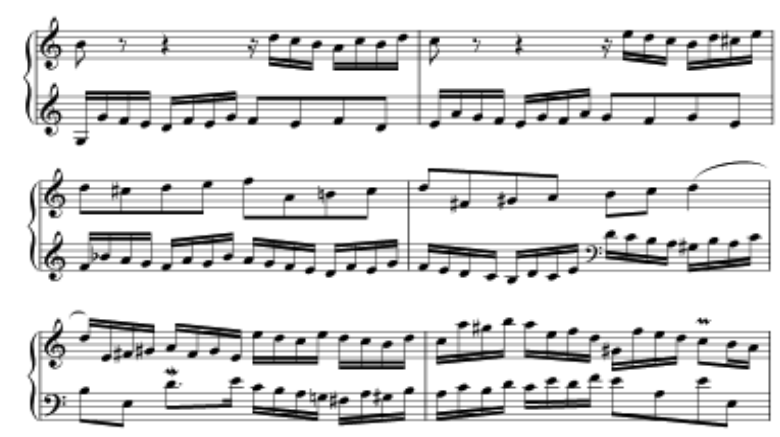

Berikut ini Invention bagian kedua yang terdiri dari birama 15-22:
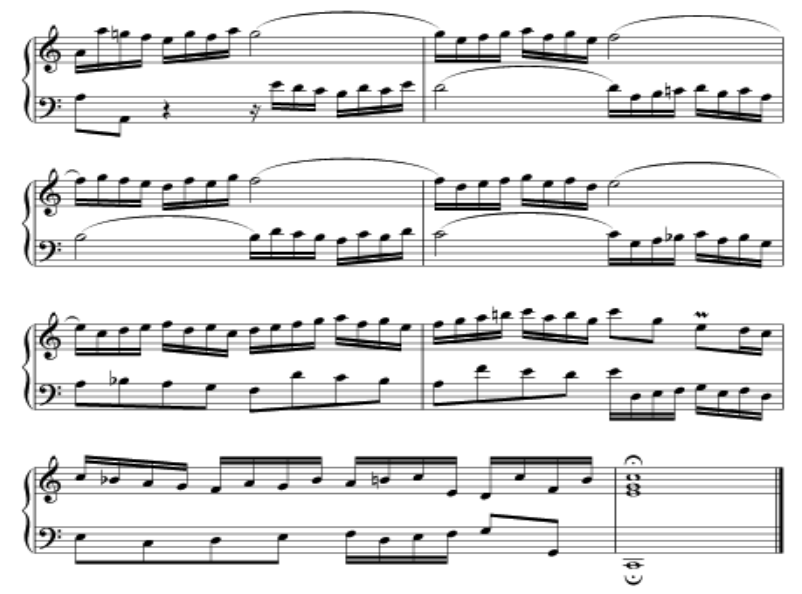

Birama 15-18 terjadi pengolahan atas motif a, dengan nada terakhir berupa orgelpung atau nada yang ditahan, yang dikerjakan dengan sekwen dan arah nadanya terbalik, serta tangga nadanya kembali ke C Mayor (birama 18).

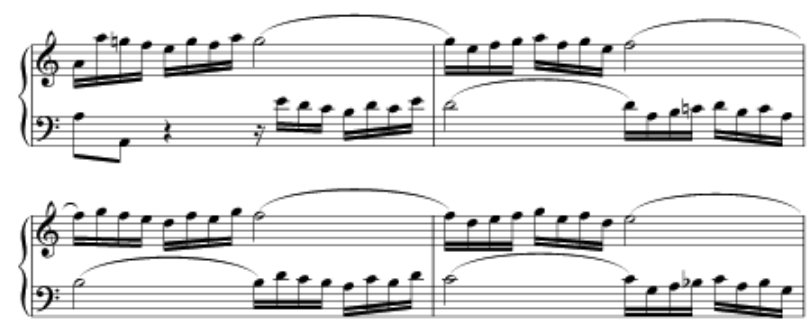

Selanjutnya, birama 19-22 sama dengan birama 3-6, namun arah nadanya terbalik dan dikerjakan dengan sekwen. Akhirnya, ditutup dengan kadens lengkap, yang didahului perjalanan akor $\mathrm{I}_{6}-\mathrm{IV}-\mathrm{V}$ I.

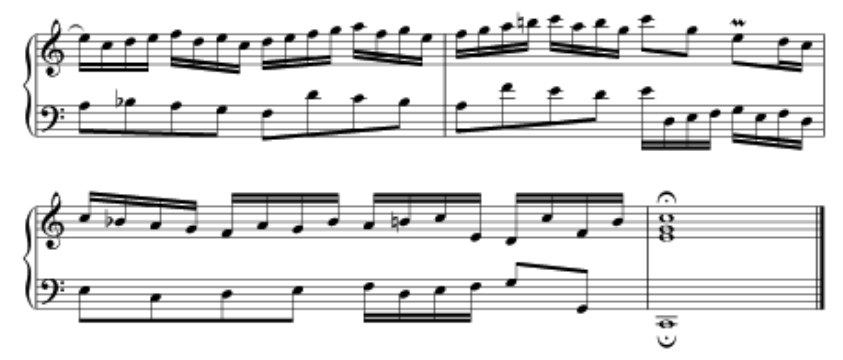

Seperti dalam kata pendahuluan, tujuan dari Invention ini adalah untuk dipakai sebagai bahan permainan piano. Bila dilihat dari segi teknik yang dipakai untuk melodi, jelas nampak keinginan Bach untuk membebaskan tangan kiri dari tangan kanan atau sebaliknya, sehingga tiap tangan mempunyai tugasnya sendiri.

\section{Penutup}

Invention No. 1 merupakan awal dari teknik komposisi yang sangat sederhana dengan pengolahan tema dan kontrapung yang juga sederhana. Teknik ini dilatih terutama dengan tujuan untuk membebaskan tangan kiri dari tangan kanan sehingga tangan kiri fungsinya sendiri, yang seolah-olah berbeda satu dengan yang lain. Dari sini dapat dilihat bahwa pelajaran piano cukup diperhatikan dalam Invention Bach.

Sebagai pola teknik komposisi, dapat dikemukakan hal-hal berikut (a) motif. Dapat dilihat bahwa Invention ini memakai motif yang dikembangkan menjadi unsur pelengkap dari seluruh komposisi.(b) Pemakaian motif ini muncul di bagian-bagian lain secara berulang di tempat yang lain, walaupun dalam tangga nada yang berbeda. Antara ulangan tersebut dijembatani oleh pemakaian motif-motif pertama, baik pertukaran fungsi tangan kanan dan kiri, maupun kebalikan motif.

Dengan sedikit penjelasan di atas, kini kita mengenal bentuk Invention sebagai sebuah komposisi piano dan bagaimana Invention ini mendorong seorang pemain piano mendalami suatu gubahan yang dimainkannya dan yang dituangkan dalam ekspresi permainannya. 


\section{Kepustakaan}

Edicrones, Parramon S.A. 1985. Bethoven. J.S. Bach Bandung: Penerbit Angkasa.

Hart, Michael H. 1982. The 100 a Ranking of the Most Influential persons in History Seratus Tokoh yang Paling Berpengaruh dalam Sejarah (terj. $\mathrm{H}$. Mahbub Djunaidi). Jakarta: PT. Dunia Pustka Jaya.

Miller, Hugh M. 1983. History of Music. London: Barnes \& Noble Books.

Rieman. 1967. Music Lexicon Sachteil. Mainz: D. Schott's Sohne.
Temperly, Nicholas 1980. "Johan Sebastian Bach" dalam Stanley Sadie, The New Grove Dictionary of Music and Musicians. London. Mac Milan Publisher. Ltd.

Thomas, Day. 1971. Music. New York: Monarch Press. Herbert H. Lehman College of the City University.

Waesberghe, F.H. Smits van. 1979. Kursus Sejarah Musik. Yogyakarta: Akademi Musik Indonesia.

Woodward, Ian 1980. Lives of the Great Composerss. Riwayat Hidup Komponis. Komponis Besar (terj: Subroto K. Atmojo). Jakarta: BPK Gunung Mulia. 